\title{
Díez interrogantes sobre el juicio notarial de capacidad: \\ Un intento de posibles respuestas
}

\author{
Leonardo Pérez Gallardo \\ Profesor Titular y Principal de Derecho Notarial de la \\ Universidad de La Habana, Cuba \\ lbpgallardo@hotmail.com
}

\section{Resumen}

A partir de disímiles interrogantes, se hace un análisis doctrinario del juicio notarial de capacidad, como juicio problemático que da el notario, en razón del desempeño de la función que le compete. Se debate sobre su carácter exclusivo o no en las escrituras públicas, y las consecuencias de su ausencia en el orden material y formal, así como de su apreciación dolosa o falsaria por el notario. Especial referencia se ofrece del juicio notarial de capacidad en personas con discapacidad psíquica o intelectual, a la luz de los postulados de la Convención de los derechos de las personas con discapacidad, aprobada en Nueva York, en el 2006.

\section{Palabras clave}

Notario / juicio de capacidad / discapacidad / incapacidad / perito / escritura pública. 


\section{Abstract}

After several questions, it is made a doctrinal analysis of the notarial judgment of capacity, as problematic judgment that the notary makes, in reason of the performance of his duties. It is debated about his exclusive character or not in the public scriptures, and the consequences of his absence in both material and formal ways, as well as its willful or fraudulent appreciation by the notary public. Special reference is offered about the notarial judgment of capacity in people with psychic or intellectual disability, based on the postulates of the Convention of the Rights of the People with Disability, approved in New York, in 2006.

\section{Key words}

Notary / Judgment of Capacity / Incapacity / Disability / Expert / Public Scripture

\section{Tabla de contenido}

1. ¿Qué es el juicio de capacidad? 2. ¿Estamos frente a un juicio problemático? 3. ¿A quién compete el juicio de capacidad? 4 . ¿De quién se da juicio de capacidad? 5. ¿Bajo qué presupuestos se da juicio de capacidad? 6 . ¿Es exclusivo de las escrituras públicas? 7. ¿Cómo debe actuar el notario cuando le abrigue dudas la capacidad del compareciente? 8. ¿Compele al notario el dictamen del perito? 9. ¿Qué consecuencias provoca el error notarial en la apreciación de la capacidad, cuáles la ausencia de mención del juicio de capacidad en la comparecencia del instrumento público, y qué otras la apreciación dolosa o falsaria de la capacidad del compareciente a sabiendas de que no la tiene? 10 . ¿Cómo valora el Tribunal Supremo el juicio notarial de capacidad?. Referencias Bibliográficas. 
La ausencia de un estudio doctrinario del juicio notarial de capacidad en el Derecho patrio amerita al menos una mirada de reojo, pues no son otras las pretensiones que este artículo tiene. Hemos estado desde antaño a la sombra de la doctrina española por los vínculos históricos que nos atan, y que hace que el Derecho español sea fuente perenne de conocimientos para los de allende el Atlántico, pero el tema amerita un esbozo dogmático de su tratamiento en el Derecho cubano, lo cual no quiere decir que otros autores no lo hayan hecho antes, pero esencialmente orientado de cara al testamento ${ }^{1}$. No se puede olvidar que el juicio de capacidad se regula en el Código Civil, solo con carácter expreso en sede testamentaria (vid. artículo 483.3).

\section{1. ¿Qué es el juicio de capacidad?}

No existe un criterio unánime en la doctrina sobre el llamado juicio de capacidad y lo digo con toda intención. No todos los autores están contestes con el nomen que a esta aseveración notarial se le debe atribuir. Si bien unos prefieren llamarle calificación notarial. Otros, por el contrario, parten de la tesis de que estamos frente a un juicio propiamente dicho, o sea, a una afirmación o negación del notario dotada de una fuerte presunción iuris tantum, o sea, susceptible de rebatirse o destruirse a través del proceso judicial adecuado, con la aportación de las pruebas destinadas a tal fin ${ }^{2}$. Según Torres Escamez “... es la declaración que realiza el notario en todas las escrituras y en algunas actas, normalmente al final de la comparecencia y antes de la calificación del acto, por la cual expresa su creencia de que los otorgantes tienen las condiciones personales de aptitud e idoneidad con arreglo a la Ley para que el acto o negocio documentado produzca sus efectos normales" . Se trata, como expresa Giménez-Arnau de “... un acto o juicio personal que no pertenece al juxta verum dictum de la fe pública, sino más bien, al principio de legalidad; juxta legem actum"4.

1 Vid. Chiкoc Barreda, Naiví, Capítulo VI “Clasificación de los testamentos”, en Derecho de Sucesiones, bajo mi coordinación, Félix Varela, La Habana, 2004, pp. 263-268.

2 El Tribunal Supremo español en su Sentencia de 21 de marzo de 1972 ha dejado dicho que: "La fe pública ampara la creencia del Notario de que el otorgante es capaz, pero no la realidad de que lo sea, por tratarse de una apreciación psíquica y no de un hecho que se exteriorice siempre por signos perceptibles por el jurista, pues para constatar la veracidad en estos casos suelen ser precisos conocimientos cientificos propios del psiquiatra, y asi la afirmación por el fedatario de que, a su juicio, es capaz el compareciente ante él, constituye una presunción 'iuris tantum' de exactitud, que los Tribunales pueden y deben revisar mediante prueba suficiente en contrario".

3 Torres Escamez, Salvador, "Un estudio sobre el juicio de capacidad”, en Revista jurídica del notariado, No. 34, Madrid, 2000, pp. 211-212.

4 Giménez-Arnau, Enrique, Derecho Notarial, Ediciones Universidad de Navarra, Pamplona, 1976, p. 530 . 
Se requiere como un prius lógico que los actos y negocios jurídicos sean el resultado de declaraciones de voluntad que se exteriorizan por personas que conocen los efectos de dicho acto o negocio, que saben discernir sobre lo que quieren, que en buen castizo están en su cabal juicio, lo cual no es sinónimo -como suele acontecer en el quehacer notarial cubano-, que no tienen la más mínima discapacidad intelectual o psíquica ${ }^{5}$. No solo se requiere capacidad jurídica, sino su dimensión dinámica, su potencialidad para ejercitar per se los derechos, lo cual en doctrina se le ha dado el nombre de capacidad de obrar, o ejercicio de la capacidad jurídica, término que emplea el legislador de nuestro Código Civil. Pero cuando ese acto o negocio se instrumenta por notario, la sola intervención de éste para la autorización del documento, le dota de certidumbre y de autenticidad a su contenido. Tal certidumbre, implica, ante todo, que el notario se ha cerciorado del discernimiento de los comparecientes, al menos ha apreciado en ellos capacidad de querer y entender lo que pretenden concertar. Como se ha dicho con acierto, la trascendencia del juicio de capacidad "radica en que ésta es el soporte del consentimiento, quien, a su vez, constituye la esencia del negocio jurídico"6.

El notario no es un perito, pero debe saber aplicar las máximas de la experiencia cuando aprecia esa capacidad volitiva de los sujetos, que le permite autorizar el instrumento público. El juicio notarial de capacidad actúa como la caja negra de un avión, es el sello indeleble en el que se sustenta la manifestación de voluntad o consentimiento, en tanto sin discernimiento, ni voluntad, no puede existir acto o negocio jurídico alguno. Solo las personas capaces pueden protagonizar un acto jurídico, y reitero hablo de personas capaces o competentes, con independencia del grado de capacidad o de competencia del sujeto, en todo caso, este será decisivo para la autorización de cada instrumento público, pero compete al notario su apreciación ad hoc.

5 Es oportuno acotar que la apreciación de la capacidad del otorgante -según expresa RodríguEZ Adrados, fue considerada históricamente ajena a la función notarial, ello a partir de la concepción puramente sensorial tenida sobre ésta. El juicio de capacidad no tenía por qué expresarse en el documento conforme con la Ley del Notariado, ni tampoco según sus reglamentos, hasta el de 1921, solo lo reconoció el Código Civil español de 1889 en materia de testamentos, al llevarse a ley lo que ya venía reconocido en dos instrucciones, una de 1861 y otra de 1874 sobre la manera de redactar los instrumentos públicos sujetos a Registro. Vid. Rodríguez Adrados, Antonio, "El documento en el Código Civil”, en Escritos jurídicos, tomo III, Colegios Notariales de España, Madrid, 1996, pp. 37-.42

Vid. Torres Escamez, S., "Un estudio sobre...", cit., p. 215. 


\section{2. ¿Estamos frente a un juicio problemático?}

Ballarín Marcial que ha estudiado con detenimiento el tema, ubica al juicio de capacidad, vía Ferrater Mora, -en un discurso más filosófico que jurídico-, entre aquellos juicios problemáticos, sustentado esencialmente en la teoría de las probabilidades $^{7}$. El notario ofrece una valoración o apreciación, como expliqué presuntiva. Es cierto que está cargada esa presunción de gran certeza o probabilidad, precisamente porque el juicio es dado por un profesional del Derecho dotado de credibilidad, pero en modo alguno perito. Empero, en todo caso tal probabilidad ha de ser objetiva o razonable. Como sostiene el autor antes citado "En vista de la conversación que el Notario mantiene con un cliente desconocido para él hasta ese momento o gracias a un examen médico previo, llega a la convicción de que, muy probablemente, es capaz, ya que se expresa normalmente, no revela ningún dato que haga sospechar, se da cuenta del negocio que va a firmar conociendo sus consecuencias prácticas..."

Es un juicio sustentado en el análisis y la deducción. Por ese motivo y dado que el ejercicio de la capacidad se presume, y no la capacidad, como suele decirse, pues esa capacidad en el entendido de capacidad jurídica la tienen todas las personas físicas por el solo hecho de serlas ${ }^{9}$, cuestión distinta lo es la capacidad de obrar, o ejercicio propio de la capacidad jurídica que si bien se presume, cabe prueba en contrario y su inversión - en el entendido tradicional-, cuando por resolución judicial de tribunal competente se incapacita a la persona.

\section{3. ¿A quién compete el juicio de capacidad?}

Como he anticipado, el juicio de capacidad es exclusivo del notario, si bien en sede testamentaria la redacción del Código Civil español (antecedente de nuestro Código Civil) lo hacía compartir con los testigos. Como en su momento adujo Giménez-Arnau "Es lamentable que la interpretación dada al artículo 685 haga compartir a los testigos del testamento una apreciación de capacidad

7 Ballarín Marcial, Alberto, "Naturaleza y clases de 'juicios' del notario “, en Anales de la Academia matritense del Notariado, tomo XXXV, Madrid, 1996, pp. 539-543.

$8 \quad$ Idem, p. 541.

9 La propia Dirección de Registros Civiles y Notarías del Ministerio de Justicia en su dictamen 3/2004, de 5 de octubre, al referirse al juicio notarial de capacidad aduce que el notario da este juicio "mediante la percepción personal que éste realiza respecto a la plena y absoluta capacidad jurídica de quién ante él comparece” (la negrita es del autor), cuando lo cierto es que dicho juicio no atañe a la capacidad jurídica, sino a la capacidad natural del sujeto que le permite obrar por sí mismo y discernir sobre los efectos del acto o negocio instrumentado, además, de que no se requiere que esta capacidad sea plena, pues el propio artículo 30 del Código Civil regula la capacidad restringida que le permite a la persona concluir válidamente actos jurídicos para los cuales no fue limitada su capacidad. 
que debería ser exclusivamente a cargo del Notario, y que se confiera a testigos imperitos un juicio jurídico para el cual, generalmente, no estarán preparados"10. Posición incómoda para los notarialistas y civilistas que resaltaron más de una vez la impropiedad del lenguaje al hacer partícipes a los testigos de la valoración de la capacidad

En el Derecho cubano tanto el artículo 64 c) en sede de escrituras públicas, como el artículo $81 \mathrm{c}$ ), en materia de actas, ambos de Reglamento notarial, como el propio Código Civil en su artículo 484.3 en lo que concierne a los testamentos, dejan explícitos que el juicio de capacidad es de la exclusividad del notario y ello forma parte de su función. El control de la capacidad en materia notarial es propio del notario, "es una facultad exclusiva del notario que se objetiviza en el momento concreto de la autorización” tal y cual ha dicho la Dirección de Registros Civiles y Notarías del Ministerio de Justicia en su dictamen No. 3/2004, de 5 de octubre, en su apartado segundo. Como ha sostenido la doctrina española "Se tratará de un juicio declarativo en que no debe haber margen racional de duda de la falta de capacidad. Y si así fuera, ni siquiera implicaría necesariamente la responsabilidad del notario, porque se limita a emitir un juicio, no una declaración de verdad"11. De ahí, lo ya expuesto sobre su naturaleza de juicio problemático, en el que juega un importante papel las probabilidades. El notario no puede dar plena certeza de que quien comparece tiene capacidad natural, pero al dar el juicio afirmativo, dota de certidumbre al acto o negocio instrumentado (y digo acto o negocio con la debida aclaración que en materia de actas, según su naturaleza, también cabe en algunos supuestos que sea necesario el juicio notarial de capacidad, aunque nuestro Reglamento lo hace extensivo a toda acta, con independencia de su propia naturaleza -extremo del cual me ocuparé a posteriori-), sometido eso sí, a la revisión judicial, cuando se impugnare el acto por falta de capacidad natural o volitiva de alguno de los sujetos intervinientes, lo que conduce a que el tribunal valore y aprecie el juicio de capacidad dado por el notario.

\section{4. ¿De quién se da juicio de capacidad?}

Resulta oportuno hacer algunas acotaciones necesarias. El juicio de capacidad recae sobre el compareciente, ya lo sea por sí, por representación, o como gestor de intereses ajenos. Quien tenga el carácter de compareciente debe someterse al juicio de capacidad.

10 Giménez-Arnau, E., Derecho..., cit., p. 528.

11 Martínez-Gil Vich, Ignacio, "Comentarios al artículo 157 del Reglamento notarial”, en Nueva legislación notarial comentada, tomo I - Legislación notarial, Colegio Notarial de Madrid, 2007, p. 413. 
Cuando se comparece como apoderado, el juicio de capacidad del poderdante lo habrá dado el notario que autorizó la escritura de apoderamiento, salvo aquellos contados casos en que el apoderamiento no consta en documento notarial, como el supuesto a que se contrae el artículo 415.2 del vigente Código Civil cuando se otorgan facultades de representación a un abogado litigante en que conforme con el dictado del mencionado precepto "Tampoco es necesaria la forma notarial (...), para realizar actos jurídicos, para lo cual bastará que el usuario deje constancia de la representación que confiere en el documento del contrato de los servicios jurídicos que suscriba", riesgo que corre la seguridad del tráfico jurídico pues cuando se concierta un contrato con el abogado, este no puede dar juicio de capacidad de su contraparte, de modo que al notario no le consta que el poderdante tenía capacidad de obrar en el momento en que concertó el contrato, todo ello por agilizar trámites legales a costa de la flaqueza de la propia seguridad jurídica ${ }^{12}$. En relación con el apoderado, dado que en Derecho quien otorga la escritura pública es el apoderado, con el concurso del poderdante, quien ha dado facultades para tal otorgamiento, y quien debe estar legitimado además, para que en su nombre y representación, concluya válidamente el acto o negocio jurídico, es sobre él (apoderado) de quien el notario dará juicio de capacidad.

El juicio de capacidad propiamente dicho se da -como expresé-, con exclusividad de los comparecientes, que son los autores del negocio o acto jurídico o también en los supuestos de ciertas declaraciones no negociales de voluntad, instrumentadas por vía de actas. En relación con los testigos y peritos, también concurrentes ocasionalmente en los instrumentos públicos ${ }^{13}$ el notario no da juicio de capacidad, se limita a controlar que estos entienden el hecho, circunstancia, acto o negocio que se instrumenta, conocen su cometido, o sea sobre qué va a versar su dictamen o la función que como testigos desempeñan en el acto notariado, y que no están incursos en ninguna de las prohibiciones comprendidas en la ley, pero no hay que confundir prohibiciones para ser testigo (vid. artículo 30 del Reglamento de la ley notarial) o para ser perito con juicio de capacidad ${ }^{14}$. Ni sustantiva, ni instrumentalmente existe un juicio de capacidad

12 Lo cual se hace más agudo en las actas de declaración de herederos ab intestato para las que el Reglamento notarial en su artículo 106 exige la comparecencia preceptiva de un abogado.

13 Sobre el tema vid. en el Derecho cubano Pérez Gallardo, Leonardo B., "Intervención testifical en los instrumentos públicos notariales: más allá de una reliquia histórica”, en Derecho Notarial, tomo II, bajo la coordinación del propio autor e Isidoro Lora-Tamayo Rodríguez, Félix Varela, La Habana, 2007, pp. 346-395 y "Concurrencia del perito en el documento público notarial”, en Revista del Instituto de Derecho e Integración, Colegios de escribanos de la provincia de Santa Fe, Rosario, Argentina, año 2, No. 4, 2010, pp. 43-102.

14 En tal sentido ha dicho la Sala Segunda de lo Civil y de lo Administrativo del Tribunal Provincial de Ciudad de La Habana, en el primer Considerando de la Sentencia No. 91 de 30 de diciembre del 2009 (ponente Pereira Basanta) al declarar SIN LUGAR la demanda interpuesta por la parte actora que "... yerra (...) cuando aduce la nulidad del instrumento notarial contentivo del negocio jurídico testamentario por incumplimiento del juicio de capacidad e identidad que debe realizar el notario de los testigos 
distinto del de los comparecientes, lo cual reitero no es sinónimo que un testigo pueda concurrir al documento, bajo los efectos de sustancias psicotrópicas o alucinógenas, pero al testigo no se le puede exigir más de lo que en Derecho corresponde, no hay un verdadero juicio de capacidad, bajo la fe pública notarial. Y en tal sentido también es dable aclarar que el notario no da fe de la capacidad mental, volitiva o natural del compareciente, lo que queda bajo su fe pública es la mención auténtica, que instrumentalmente imponen nuestras normas reglamentarias notariales, esto es, de que ha dado juicio de capacidad, que se ha cerciorado de que el compareciente tiene discernimiento para realizar válidamente el acto o negocio en cuestión y así está en el deber de consignarlo en el instrumento, de modo que se convierte en una solemnidad que en materia testamentaria tiene un plus al venir regulada en el artículo 483.3 del Código Civil, pero que igualmente impone el Reglamento notarial para los demás instrumentos públicos. Ahora bien, tradicionalmente se ha entendido que el notario da juicio de capacidad de sujetos perfectamente competentes para realizar válidamente actos o negocios jurídicos. Y a tal fin, en la manera en que se han interpretado las normas jurídicas el juicio de capacidad afirmativo se orienta hacia personas plenamente capaces, ya sea porque han arribado a la mayoría de edad o porque antes de arribar a esta han formalizado matrimonio (vid. artículo 29 del Código Civil), lo cual sin dudas es un error, y ello motivado por varias razones. Se hace un olvido reiterado de la regulación en el Código Civil de la capacidad restringida, situación en la que pueden estar incursas las personas a las que el tribunal les ha limitado la válida conclusión de ciertos actos jurídicos.

El Código Civil vigente brinda la posibilidad de que los menores de edad, mayores de diez años, puedan realizar válidamente ciertos actos jurídicos, a juicio del legislador aquellos que sean necesarios para satisfacer sus necesidades normales de la vida diaria, así como disponer del estipendio que les haya sido asignado y cuando alcancen la edad laboral (en nuestros predios de 17 años) disponer de su retribución. La norma tiene su origen en los códigos civiles de Europa del Este, y hoy día resulta a muy pesar, prácticamente letra muerta. Aun con la ortodoxia del precepto en materia de capacidad progresiva, en tanto no se establece una gradación de la edad que permita, en la medida en que el menor alcance ciertas edades, próximas a los 18 años, poder concluir ciertos actos jurídicos, como el testamento, para el cual el Código Civil español que nos rigiera por casi un siglo preveía los 14 años, y precisamente un siglo después se elevó paradó-

que intervienen en el acto, toda vez que no se recoge en la Ley de Notarias Estatales ni en su Reglamento la obligación para el funcionario notarial de emitir juicio de capacidad de los testigos, quienes participan en el acto bajo el carácter de testigos instrumentales a los meros efectos de constatar el cumplimiento de las formalidades legales conforme establece el artículo cincuenta y dos del citado Reglamento; exigiéndose la emisión del juicio de capacidad sólo para las personas que comparecen ante notario a fin ejercer su capacidad jurídica de obrar mediante la realización de actos jurídicos relacionados con su persona o su patrimonio para lo cual es necesaria la dación de fe pública que brinda el notario sobre la capacidad del compareciente (...)". 
jicamente a 18 años, sin una razón que permita al menos disentir, pues es hartamente conocido que el testamento no surte efectos jurídicos sino a la muerte de su autor, y que en nada compromete su patrimonio ante mortem, por ser revocable usque ad mortem. Como expresa la profesora VALDÉs DíAZ "debe interpretarse el enunciado general del artículo 30 en sentido positivo, esto es, entender que tienen capacidad suficiente para realizar todos los actos que de un modo u otro contribuyan a satisfacer sus propias necesidades cotidianas, $\mathrm{y}$ que las restricciones recaen sobre otros actos distintos, para los cuales necesitaría complementar su capacidad a través de la institución de guarda que corresponda" ${ }^{15}$. El enunciado del legislador es lo suficientemente abarcador como para admitir la comparecencia de menores en actos que supongan una mera administración o conservación de su patrimonio. Si se ofrece una interpretación evolutiva del precepto en cuestión no cabe dudas que al menor le es dable disponer por sí, sin necesidad de sus representantes legales (sean los progenitores o los tutores) de lo que por concepto de pensión alimenticia recibe, porque qué debe entenderse por estipendio. Solo excepcionalmente, y a partir de los 15 años, el menor podría, previa autorización, desempeñar un puesto de trabajo, ergo, no tendría antes otra posibilidad de recibir dinero que no fuera por una donación o cualquier otra liberalidad, pero hoy día los menores también reciben ciertas remesas familiares, en esencia provenientes del extranjero, ya sea de sus progenitores o de otros familiares, como abuelos, hermanos y tíos, las que suelen recibirse con cierta periodicidad y que al tipo de cambio en moneda nacional, pueden significar cierto valor patrimonial ¿¿Deben entenderse comprendidas estas remesas en el concepto de "estipendio" que da el Código Civil? ¿Pudiera comparecer el menor de edad, mayor de 10 años, a realizar un acto dispositivo de dicha remesa a los efectos de adquirir ciertos bienes sin representación de sus progenitores?.

La respuesta a priori, sería negativa. Tenemos una visión de la capacidad bicolor, no hay matices en la manera en que se han venido aplicando los escasos preceptos reguladores de la materia, pero lo más significativo es que un artículo como el 30 de nuestro Código Civil, en 1987, cuando se aprobó dicho cuerpo legal, era verdaderamente un impulso de oxígeno en la vetusta concepción del ejercicio de la capacidad de los menores, con la que tradicionalmente nos hemos formado ${ }^{16}$.

15 Vid. VAldés Díaz, Caridad del C., "Comentarios al artículo 30", en Comentarios al Código Civil, tomo I - Disposiciones preliminares. Relación jurídica, volumen I (artículos 1 al 37), bajo mi dirección, Félix Varela, La Habana, 2013, pp. 498-499.

16 Así, según el Tribunal Supremo “(... la aptitud para el ejercicio de los derechos y para concluir actos jurídicos, o sea, la posibilidad de realizar actos con valor y eficacia que determina la capacidad de gestionar los propios actos jurídicos y por ende confiere la posibilidad de que un sujeto influya en su propia situación con su voluntad dirigida bien a crear relaciones jurídicas, a extinguirlas o a modificar aquellas de las que era su titular presupone, por tanto, la madurez de la voluntad, que le 
Es claro el artículo 28 de la ley notarial cuando establece que "Son incapaces para comparecer en los actos que autoriza el Notario, los menores de dieciocho años de edad, excepto en los casos en que la ley lo autorice expresamente (...)”, de modo que amén del error conceptual en que incurre, al pretender hacer coincidir la plena capacidad de obrar con la mayoría de edad, lo que se desdice en el artículo 29.1 b) del Código Civil, dado que también la plena capacidad para realizar actos jurídicos y ejercitar derechos se adquiere con el matrimonio de los menores de edad, y puntualizo que tal capacidad es plena, pues a diferencia de otros ordenamientos jurídicos ${ }^{17}$, el menor casado puede realizar válidamente cualquier acto jurídico, salvo aquellos para los que se exigen capacidades especiales como la adopción, pero en materia patrimonial un menor de edad, casado, no tiene limitación alguna para el ejercicio de los derechos de los que es titular. No obstante, el precepto está en plena armonía con el artículo 30 del Código Civil, ergo, los menores de 18 años, mayores de 10 años, pueden comparecer ante notario para concluir válidamente actos en los que dispongan no solo de su estipendio, sino de lo que por similar concepto reciba, como pueden ser remesas familiares, o su crédito alimentario, en actos, aún dispositivos, con los que pretendan satisfacer sus necesidades de la vida diaria, concepto válvula establecido por el legislador, que hay que interpretar no conforme con el momento de su sanción, sino con el de su aplicación, al haber cambiado notoriamente las circunstancias que primaban en la década de los años 80 , sobre lo que era indispensable para que un menor pudiera satisfacer sus necesidades de la vida diaria.

Puede ser discutible que el menor en tales casos no asista con sus progenitores, quienes complementarían el ejercicio de su capacidad, pero la solución legislativa es clara: si se trata de estos actos, el menor tiene pleno ejercicio de su capacidad y puede concluir válidamente el acto, sin necesidad, ni tan siquiera de ser asistido por sus padres. Corresponderá al notario ponderar las circunstancias, sobre todo a partir de subsumir el acto o negocio jurídico que se pretende concertar en el dictado del artículo 30 del Código Civil, de tal modo que la complejidad del acto y su naturaleza, sobre todo si es dispositiva de cierta cantidad de dinero, pudieran constituir circunstancias a tener en cuenta por el notario, antes

permita querer jurídicamente, existiendo en el caso de la minoría de edad un supuesto prohibitivo de la capacidad de obrar que da lugar a la representación legal por dicha circunstancia natural (...)", Sentencia No. 832 de 22 de diciembre del 2006, primer Considerando, ponente Arredondo Suárez. Obsérvese que el pronunciamiento del Tribunal niega la capacidad progresiva del menor. Todo menor, por el hecho de serlo, no puede ejercitar su capacidad de obrar. No se tienen en cuenta las distintas etapas por las que atraviesa la maduración del intelecto de los menores.

17 Solo a modo de ejemplo, consúltese el artículo 323 del Código Civil español. 
de tomar la decisión de autorizar o no, el instrumento que pretendiera el menor. También es cierto que en la redacción del artículo 30 a) del Código Civil no se piensa en clave notarial, esto es, los actos que realiza el menor para satisfacer sus necesidades de la vida diaria, son entendidos como actos de la vida cotidiana, la compra en establecimientos comerciales, en las redes de tiendas, en cafeterías e incluso restaurantes, pero no en sede notarial. Empero, entenderlo de ese modo sería negar la capacidad progresiva del menor, una de cuyas pocas expresiones de reconocimiento legal en Cuba lo es el artículo 30 del Código Civil. Nada priva entonces que los menores protagonicen estos actos en sede notarial, de la misma forma que adquieren un helado, podrían adquirir un electrodoméstico y decidir qué tal adquisición sea ante notario público, tal electrodoméstico pudiera solventar hoy día una necesidad de cualquier menor en su vida diaria. Tampoco quita, pues no hay prohibición, que se ejercite alguno de los derechos inherentes de la personalidad por el menor, instrumentado tal ejercicio ante notario público. Aunque en nuestro Derecho se desconoce la categoría de los menores adultos, resulta risible que un adolescente se convierta en plenamente capaz al arribar a los 18 años y un día antes no pueda comparecer por sí en ninguna escritura pública, lo que hoy día acontece en nuestros despachos notariales, ni tan siquiera para reconocer la filiación, nacida durante la minoridad del progenitor. Continuamente nos amparamos en la Convención de los derechos del niño, pero ese interés superior del cual se habla tanto, implica, entre otras tantas razones, el que al menor no solo se le escuche en procesos judiciales y se tomen todas las medidas tendientes a proteger su patrimonio, sino también el reconocimiento de una capacidad progresiva, que le permita en la medida que va madurando ser partícipe por sí mismo de los más elementales actos jurídicos civiles y del ejercicio de sus propios derechos.

La capacidad restringida ha de entenderse como el reconocimiento de potencialidades en el sujeto de derecho. La persona, en principio, puede realizar todos los actos jurídicos civiles, salvo aquellos para los cuales la resolución judicial de incapacitación así lo ha previsto. Por ese motivo ha de verse como lo que es: una excepción al pleno ejercicio de la capacidad de obrar del agente, solamente restringida, con las garantías procesales, cuando al efecto así ha sido probado ante el órgano judicial. Lo que es de lamentar es la tendencia que existe en nuestra práctica judicial de declarar judicialmente incapacitada a la persona en supuestos en los que no se explora las posibles potencialidades del sujeto, ello impulsado además por la carencia de instituciones de guarda y protección que tengan por finalidad solo la asistencia de las personas con discapacidades psíquicas o intelectuales, y no el régimen de suplencia del ejercicio de dicha capacidad a través de la figura de la tutela. Como expone la profesora VAldés DíAz, ante 
esta situación de anomia en el régimen de asistencia de las personas con discapacidad psíquica o intelectual, "lo común, ante la ausencia de otras figuras más idóneas, es reconducir al sujeto con capacidad restringida a las normas del Código de Familia en sede de patria potestad o tutela, en franca contradicción con el pretendido objetivo de ofrecer mayores posibilidades de actuación a las personas que encajan en los supuestos del comentado artículo 30 del Código Civil”18.

Esta posición denunciada por la mencionada profesora - a la que me afilio-, va en franca contradicción con el espíritu y la letra del Código Civil y con la de la Convención de los derechos de las personas con discapacidad, igualmente ratificada por Cuba. Esa visión reduccionista de las potencialidades de la persona con discapacidad psíquica o intelectual va en desmedro del ejercicio de sus derechos. El discernimiento o voluntad del sujeto no puede medirse en términos matemáticos, concretamente en ese lenguaje binario importado de las ciencias de la computación, de modo que se es capaz o incapaz, menor o mayor de edad. Nada más lejos de la verdad que seguir estos derroteros ${ }^{19}$. Compete al notario controlar la capacidad natural del sujeto en el momento mismo del otorgamiento, de la misma manera que el tribunal ha de presumir que la persona sobre la cual se interesa sea declarada su incapacitación, tiene potencialidades que le permiten discernir en ciertas circunstancias. La incapacitación ha de ser excepción, solo en casos extremos, ante determinadas discapacidades intelectuales profundas o severas que obnubilan toda posibilidad de discernimiento.

La Convención de los derechos de las personas con discapacidad, ratificada por Cuba en el 2007, supone un cambio de paradigmas en la manera en que debe entenderse el ejercicio de la capacidad jurídica de las personas con discapacidad. Y a pesar de que el artículo 20 del Código Civil regula que "Si un acuerdo o un tratado internacional del que Cuba sea parte establece reglas diferentes a las expresadas

18 Valdés Díaz, C. del C., "Comentarios al...”, cit. , p. 497.

19 Expone el profesor Parra Benítez en su estudio sobre la Ley 1306 de 31 de julio del 2009, que adapta el Derecho interno colombiano (Código Civil) a los retos que ha impuesto la Convención de los derechos de las personas con discapacidad, estableciendo un nuevo régimen jurídico de los incapaces, que en el informe de ponencia para primer debate en el Senado de la mencionada Ley se dijo: "Se abandona la antinomia entre 'capacidad' jurídica enfrentada 'incapacidad' que han tenido las legislaciones precedentes, a efecto de reconocer y hacer eficaz la voluntad de la persona en aquellos temas y campos en que se desenvuelve con ventaja en la sociedad, las cuales van desde unas pocas actuaciones que lo pueden beneficiar, en las personas gravemente afectadas, hasta prácticamente todos los campos del Derecho en los que tienen su intelecto sano, pero actúan de manera descontrolada en el manejo de su patrimonio, reconociendo que se trata de un espectro de discapacidad considerablemente amplio". Vid. Parra Benítez, Jorge, El nuevo régimen de incapaces en el derecho colombiano. Ley 1306 de 2009, Pontificia Universidad Javeriana, Grupo editorial Ibáñez, Depalma, Bogotá- Buenos Aires, 2011, pp. 97-98. 
en los articulos anteriores o no contenida en ellos, se aplican las reglas de dicho acuerdo o tratado", razón por la cual tendrá preeminencia la norma internacional sobre la interna y que ha llevado a la doctrina patria a expresar que en dicho precepto "se establece una solución a los supuestos en que se produzca alguna contradicción entre el tratado y la norma interna, disponiendo que, en el caso de que la solución dada por el tratado sea diferente a la prevista en la norma interna, resultará de aplicación la regla que en su caso establezca dicho acuerdo o tratado; por tanto, el tratado se incorpora a la legislación del Estado alcanzando igual valor que la ley e incluso superándola en determinados supuestos" ${ }^{20}$, no obstante, no hay una validación de lo reconocido en el artículo 12.4 de la citada Convención, en el sentido de que "en todas las medidas relativas al ejercicio de la capacidad jurídica se proporcionen salvaguardias adecuadas" a tono con el respeto de "... los derechos, la voluntad y las preferencias de la persona, que no haya conflicto de intereses ni influencia indebida, que sean proporcionales y adaptadas a las circunstancias de la persona, que se apliquen en el plazo más corto posible y que estén sujetas a exámenes periódicos, por parte de una autoridad o un órgano judicial competente, independiente e imparcial", a la vez que sean "proporcionales al grado en que dichas medidas afecten a los derechos e intereses de las personas". Ello a muy lamentar no se refleja en los autos judiciales de incapacitación ni tampoco en las sentencias del Tribunal Supremo, el cual sigue aferrado a una concepción rígida del ejercicio de la capacidad jurídica, de manera que se entiende "que la integridad mental por ser atributo normal del ser humano se presume en toda persona que no haya sido previamente declarada incapacitada por tribunal competente" (Sentencias Nos. 285 de 7 de octubre del 2009, primer Considerando, ponente Arredondo Suárez, 43 de 26 de febrero del 2010, único Considerando, ponente Arredondo Suárez, 113 de 30 de abril del 2010, primer Considerando, ponente Arredondo Suárez), lo cual nos permite colegir que para el Alto Foro la declaración judicial de incapacidad cercena toda integridad mental del sujeto, que carecería de cualquier posibilidad de actuación per se. Se tiene la percepción de que la recuperación del ejercicio de la capacidad es sumamente excepcional, no opera una revisión periódica, ni se restringe el ejercicio de la capacidad de manera temporal.

Esta percepción se traspola a sede notarial. Declarada judicialmente incapacitada una persona, se le veda toda posibilidad de ejercitar per se los derechos de los cuales es titular, y no se permite explorar su preferencia ni para los más vitales actos jurídicos. Según el Tribunal Supremo "mientras una persona no esté declarada incapacitada es necesario probar la falta de capacidad en cada uno de los actos

20 Vid. Pérez Silveira, Maelia Esther, “Comentarios al artículo 20”, en Comentarios al Código Civil cubano, tomo I - Disposiciones preliminares y Relación jurídica, volumen I (artículos 1 al 37), bajo mi dirección, Félix Varela, La Habana, 2013, p. 323. 
que realice el presunto incapaz, en cambio una vez que se obtiene la aludida declaración judicial, todos los actos en que intervenga serán por fuerza nulos sin necesidad de prueba alguna (...)" (Sentencia No. 714 de 31 de octubre del 2003. Cuarto Considerando. Ponente Arredondo Suárez). Así de sencillo: tras la declaración judicial de incapacidad, se entiende que la persona carece de total discernimiento, de modo que no le sería posible al notario autorizar instrumento público alguno, y con ello se conculca el sentido del artículo 12.4 de la Convención de los derechos de las personas con discapacidad. Pensar de esta manera supone cercenar las diversas posibilidades de actuación de una persona que en razón de su discapacidad le ha de ser tan solo restringido el ejercicio de su capacidad jurídica y no cegarle este ${ }^{21}$.

\section{5. ¿Bajo qué presupuestos se da el juicio de capacidad?}

No hay reglas preestablecidas sobre el juicio de capacidad. Como expresa GóMEZ TABOADA el notario no tiene herramientas especializadas para dar el juicio de capacidad, solo dispone "En principio, con su sentido común y con su experiencia -tanto personal como profesional"22. Para Ballarín Marcial "El examen por el Notario, mediante una conversación de cierta envergadura con el interesado, bastará en la mayoría de los casos para cerciorarse de que sabe lo que va a firmar y conoce sus consecuencias jurídicas y prácticas, que es (...) como debe medirse la capacidad"23.

Apunta Martínez Díe que "En definitiva, el juicio notarial de capacidad debe sujetarse a los principios de inmediación, de legalidad y de responsabilidad, que permitan construir los cimientos sobre los que deben sustentarse cuantos análisis se hagan sobre esta materia" ${ }^{24}$. Ciertamente el juicio de capacidad no puede

21 Expone el profesor Parra Benítez que tras la aprobación de la Ley 1306 del 2009, ha operado un cambio sustancial en la concepción de los supuestos de incapacitación judicial. Así, "la incapacidad absoluta de los discapacitados mentales absolutos (y parcialmente la de los impúberes) no es en la actualidad una situación jurídica que impida en cualquier caso actuar jurídicamente al incapaz. Esas disposiciones, por el contrario, le permiten celebrar actos gratuitos, actos bilaterales onerosos útiles, actos y negocios jurídicos familiares y, en fin, constituir relaciones jurídicas de carácter laboral”.

Igualmente el concepto de incapacidad relativa también cambió en esencia. "Hoy (...) el discapacitado mental relativo, que es incapaz relativo, no cuenta con una incapacidad general sino que su incapacidad está limitada a los actos que precise el juez". Vid. PArra Benítez, J., El nuevo régimen..., cit., pp. 105 y 107, respectivamente.

22 Gómez Taboada, Jesús, "Capacidad del otorgante y vicios del consentimiento", en Derecho Notarial, tomo II, Leonardo B. Pérez Gallardo e Isidoro Lora-Tamayo Rodríguez (coordinadores), Félix Varela, La Habana, 2007, p 334.

23 Vid. Ballarín Marcial, A., "Naturaleza y clases...”, cit., p. 532.

24 Vid. Martínez Die, Rafael, "El juicio notarial de capacidad en su dimensión negativa: régimen jurídico y consecuencias", en La Notaría, No. 2, mayo 2002, p. 65. 
establecerse sobre la base de un procedimiento rígido y formal, pudiera el notario aplicar un test psicológico a los comparecientes, pero no creo que ganaría mucho con ello. El Derecho notarial se informa como uno de sus principios medulares de la inmediación. No se concibe que el notario pueda dar un juicio de capacidad de alguien que no tiene frente a sí. Se hace imprescindible que como el médico que ausculta al paciente, el notario indague y explore la voluntad de quien concurre ante él, que determine si realmente puede exteriorizar esa voluntad, libre y de manera espontánea, ajustándola a las verdaderas intenciones del sujeto, sobre la base de la presunción general de capacidad, la cual en principio cede ante la declaración judicial de incapacitación, pero no obstante, aún existente ésta habrá que indagar qué actos en concreto le han sido restringidos a la persona, la incapacitación absoluta, debe ser concebida como excepción, y no como regla. De ahí que no comparta, en todo, la opinión del propio MarTínez Díe cuanto expresa de manera demasiado categórica, en mi criterio, de que "La gran diferencia entre las causas legales de incapacitación y la incapacidad apreciable por Notario es de índole temporal, ya que aquéllas deben proyectarse hacia el futuro de forma 'persistente', es decir, tienen que ser de suficiente entidad como para crear un estado permanente, mientras que éstas pueden ser resultado de un estado transitorio y provisional. $Y$ así, en tanto que a la incapacitación judicial le interesan el presente y el futuro, a la actuación notarial de rechazo sólo le interesa el presente". Y es lo cierto que esa vocación de perennidad ha sido con la que se ha estudiado la figura de la incapacitación. Cuesta trabajo entender, incluso por los operadores jurídicos, que es posible restablecer el ejercicio de la capacidad de una persona, y mucho más, pensarlo con esa comprensión de temporalidad que hoy nos recuerda la Convención de los derechos de las personas con discapacidad cuando en su artículo 12.4 convoca a los Estados partes a que proporcionen a las personas con discapacidad, a los efectos del ejercicio de su capacidad jurídica "salvaguardias adecuadas (...) sujetas a exámenes periódicos por parte de una autoridad o un órgano judicial competente, independiente e imparcial", con lo cual desaparece esa noción de perennidad e infinitud con la que suele estar asociada la declaración judicial de incapacitación, si bien el propio Código de Familia cubano, en ocasión de regular la tutela le impone al tutor "procurar que el incapacitado adquiera o recupere su capacidad" (cfr. artículo 153.2), o sea, que aun cuando la declaración judicial de incapacitación nunca ha sido concebida como irrevocable, los Derechos internos de los Estados no han tendido a imponerle a los tribunales la necesidad de que en las resoluciones judiciales en que se contiene la declaración misma de incapacitación se disponga el período en que debe ser preceptivamente revisada la propia declaración, esa revisión constante que busca la posibilidad de explorar continuamente las facultades mentales y volitivas de la persona sometida a un régimen de incapacitación, el que por demás resulta excepcional a tono con la propia Convención. 


\section{6. ¿Es exclusivo de las escrituras públicas?}

Al ser las escrituras públicas reservorio de los actos y negocios jurídicos, en el que la voluntad es presupuesto mismo de su existencia, el ejercicio de la capacidad jurídica se torna en pilastra misma de esa voluntad, no hay voluntad, sin que el sujeto pueda ejercer per se la capacidad jurídica y tenga plena capacidad jurídica para el acto o negocio jurídico que pretende instrumentar. La cuestión se torna mucho más polémica en sede de actas notariales dada su propia naturaleza. Entre los notarialistas españoles TAmayo Clares es partidario de que el juicio de capacidad sólo debe referirse técnicamente a las declaraciones de voluntad, y en tal sentido en las actas éste resulta innecesario, siendo suficiente hacer constar el interés legítimo, que ha de estar en relación con la licitud misma de la actuación notarial, siendo suficiente la capacidad general de obrar. No obstante, el propio autor identifica algunos tipos de actas en las cuales, vía reglamentaria, puede colegirse la necesidad del juicio de capacidad, entre ellas las actas de subasta y la del administrador que solicite la presencia del notario en una junta general de una sociedad ${ }^{25}$. Como establece el artículo 198.1-10 del Reglamento notarial español, en relación con las actas, "En la comparecencia no se necesitará afirmar la capacidad de los requirentes (...)", si bien el precepto propiamente dicho se refiere al acto de rogación contenido en las actas notariales. Acota RodRíguez Adrados que la rogación no exige capacidad especial, es suficiente la capacidad natural de entender y de querer, pero no la capacidad negocial que se exigen para las escrituras públicas a partir de su contenido. Por ello -al sentir del reconocido maestro -, no es necesario formarse y expresar un juicio de capacidad en dichos instrumentos $^{26}$. De la CÁmara Álvarez incluye la no necesariedad del juicio de capacidad en las actas como un elemento que le distinguen de las escrituras públicas $^{27}$. En fecha más reciente los autores que han comentado el mencionado artículo reglamentario han expresado -en criterio que comparto-, que compete al notario ponderar en qué casos debe invertirse esa regla general que en materia de actas establece el citado artículo $198.1-1^{\circ}$ pues de tratarse de actas

25 Vid. Tamayo Clares, Manuel, Temas de Derecho Notarial, 5a edición, Ilustre Colegio Notarial de Granada, Granada, 2001, pp. 137-138.

26 Vid. Rodríguez Adrados, Antonio, “Cuestiones de técnica notarial en materia de actas”, en Escritos jurídicos IV, Colegios Notariales de España, Madrid, 1996, pp. 61-62.

27 Vid. Cámara Álvarez, Manuel de la, "El notario latino y su función”, en Revista de Derecho Notarial, año LXXVI, abril-junio 1972, p. 90. El propio autor sostiene que "La capacidad en sentido técnico sólo puede referirse a declaraciones de voluntad. Y este tipo de actas (se refiere a las de mera constatación de hechos) no contiene ninguna. La única capacidad exigible al requirente es la necesaria para impetrar la intervención notarial, que, por cierto, no está establecida en parte alguna. Debe estimarse, pues, que basta la capacidad de obrar general", p. 95. 
en las que se ejerciten derechos, incluidos facultades y derechos potestativos, el notario sí que debe dar un juicio de capacidad y de legitimación del rogante para instar la autorización misma del acta (en mi criterio v.gr., en las actas de notificación o de requerimiento). Sostienen dichos autores que "Estas normas generales no descienden a precisar en qué casos basta con que el requirente tenga 'interés legítimo' y en qué casos la comparecencia e intervención deben ser más completos, como si de una escritura pública se tratase. Es lógico que así sea, porque la variedad de situaciones que instrumentan las actas hace necesariamente incompleta cualquier enumeración. Así, no se precisan las mismas cualidades subjetivas para requerir del notario que haga constar la existencia de una señal de tráfico en una calle, que para constituir un depósito o para tramitar una subasta. Es el notario quien debe tomar en cada caso la decisión adecuada teniendo en cuenta la actuación para la que se le requiere"28.

La posición de la doctrina más reciente española enunciada nos pone en alerta a los notarios. El juicio de capacidad en materia de actas notariales, ha de ser apreciado casuísticamente por el notario. Le corresponde a él determinar conforme con el contenido de cada acta en concreto, si es dable apreciar la capacidad del sujeto, lo que no debe ser confundido en ningún caso, ni en materia de actas, ni de escrituras, con el juicio de legitimación que igualmente le compete para determinar la especial situación jurídica en la que se encuentra el requirente o el compareciente en relación con el hecho, acto, negocio o circunstancia instrumentada que le habilita en ese orden para actuar. Así, v.gr., el vendedor tiene que acreditar la titularidad que tiene sobre el bien, el notario, por su parte calificará el documento que le confirma como propietario, o sea, el título formal que justifica su condición de titular del dominio, de este modo el notario dará un juicio de legitimación del vendedor, tras comprobar además que no se erigen prohibiciones para contratar en dicho sujeto, pero aún así, cabría la abstención del notario si no aprecia que el pretenso vendedor tiene capacidad de obrar, amén de su discapacidad, de manera que no puede autogobernarse y perfilar los efectos que para él supone un contrato de compraventa, son dos conceptos distintos que hay que saber distinguir. Al decir de Torres Escamez "Sin entrar en demasiadas profundizaciones, creo que debe quedar claro que la titularidad y la legitimación son aspectos necesarios para el control de legalidad que realiza el notario, pero distintos de la capacidad, figura que se basa en las condiciones personales del compareciente" 29 .

28 Vid. Solís Villa, Carlos, y Francisco Javier Morillo, "Comentarios al artículo 198 del Reglamento notarial”, en Nueva legislación notarial comentada, tomo I - Legislación notarial, Colegio Notarial de Madrid, 2007, p. 560.

Vid. Torres Escamez, S., “Un estudio sobre...”, cit., p. 221. Con anterioridad, en una posición que 
Mucho más rígida - y diría yo inconcebible-, es la posición de nuestro Reglamento notarial que exige en toda acta notarial, sin sopesar en su naturaleza y contenido, el juicio notarial de capacidad en el artículo 81 c), con la inevitable consecuencia, y absurda a la vez de que su omisión en el instrumento conduzca a su nulidad ex artículo 16 b) de la Ley notarial, interpretación literal que no racional de la norma, pues resulta ilógico v.gr., que un menor de edad no pueda requerir al notario para la autorización de un acta de mera percepción.

\section{7. ¿Cómo debe actuar el notario cuando le abrigue dudas la capacidad del compareciente?}

El artículo 54 de nuestro Reglamento notarial establece la concurrencia del médico al documento público. Precepto que aunque diáfano y claro ha tenido que ser interpretado por la Dirección de Registros Civiles y Notarías del Ministerio de Justicia para su homogénea aplicación, sobre todo en sede testamentaria.

Es dable elogiar la fórmula de nuestro autor del Reglamento que le da un matiz puramente notarial, a un tema que en los códigos civiles decimonónicos venía reservado, con exclusividad, a la figura del testamento, con una estrechez inusual en los legisladores de la época. Téngase en cuenta que la fórmula reglamentaria hace permisible la concurrencia del médico en cualquier instrumento notarial, incluso en las actas notariales, en las que como expresé, caprichosamente se exige juicio notarial de capacidad, así sea su naturaleza (vid. artículo $81 \mathrm{c}$ )).

El artículo 54 aunque alude al dictamen pericial, como prueba que se practica, no desliga ella del medio de prueba, esto es, del perito en sí, de modo que el dictamen lo ha de ofrecer el perito en presencia física del compareciente y del notario, en plena audiencia notarial, ergo, él sería uno de los sujetos protagonistas de la audiencia notarial. Su ausencia sería motivo del quebrantamiento de la unidad de acto formal que exige el artículo 35 del Reglamento notarial con alcance general y que refuerza el artículo 484.4 del Código Civil en sede testamentaria. A este fin la Dirección de Registros Civiles y Notarías del Ministerio de Justicia ha dejado dicho en su Dictamen No. 3/2004 de 5 de octubre que: "en los supuestos en que el notario precise de un pronunciamiento pericial respecto a la capacidad mental

tiende al confusionismo en este orden, López GARzón había conectado la legitimación y la capacidad, pero en el sentido de que la primera estaba embebida en la segunda. A criterio de dicho autor la legitimación se incluye en el juicio de capacidad del notario. Para él el juicio de capacidad es la única apreciación jurídica que del compareciente hace el notario. Su tesitura se mueve hacia la responsabilidad notarial por el juicio de capacidad, de modo que refuta la doctrina precedente que intenta ubicar lo que hoy se conoce como legitimación en el juicio de identidad. Vid. López Garzón, José, “Titularidad y fe de conocimiento", en Revista de Derecho Notarial, No. 7, Madrid, 1955, pp. 269-278. 
del compareciente al instrumento público, ésta se verifique mediante la intervención directa, en el acto en cuestión y ante el notario autorizante, del perito o facultativo que certifique la condición de esta persona, lo que se hará constar en la escritura o acta según sea el caso, en la parte correspondiente a la comparecencia, con independencia de la obtención previa, de un documento especializado que la certifique”.

Se exige del médico el necesario cumplimiento del principio de inmediación. Quien dictamina sobre el estado mental y la capacidad volitiva del compareciente tiene que hacerlo en el momento en que se instrumenta el acto, ni antes, ni después. Debe el médico en tales circunstancias concurrir al instrumento, y dejar graficada su presencia a través de su firma. El dictamen, a mi juicio, se rinde oralmente, es ilógico que se haga antes del momento mismo del otorgamiento y autorización o que se haga después ${ }^{30}$. Si se hizo antes, entonces no se está esclareciendo las dudas que el notario tiene en ese momento, con independencia de que el médico en un dictamen por escrito venga diciendo que el sujeto en el momento en que él lo examinó sí tenía esa capacidad volitiva, la cual pudo perfectamente desaparecer después, por tan disímiles causas, que no vienen al momento explicar, además de que no soy perito precisamente en ese tema. $\mathrm{Si}$ se hace después, con referencia al momento en que se apreció la capacidad, en plena audiencia notarial, entonces el dictamen escrito tendría que pasar por el proceso de legalización, lo que conllevaría que su fecha no correspondería con la del acto de otorgamiento y no le es dable al notario adjuntar a la matriz un documento fechado con posterioridad a dicho acto ¿ $Y$ en todo caso qué utilidad ello tendría? ¿No acude el médico a instancia del notario, a los efectos de despejar las dudas que la abriga la capacidad del compareciente? ¿No es en definitiva el notario el único que da el juicio de capacidad? No se olvide que el médico funge como auxiliar del notario, en modo alguno le sustituye y su dictamen pericial no le compele a autorizar el documento o a negar su dación de fe. Por ese motivo comparto el razonamiento esgrimido en el citado Dictamen cuando se deja esclarecido que: "La obtención, previo a la formalización del documento notarial, del dictamen pericial, implica que el análisis realizado por el facultativo, se

30 Según el criterio de la Sala de lo Civil y de lo Administrativo del Tribunal Supremo, vertido en el primer considerando de la Sentencia No. 266 de 28 de febrero del 2001 (ponente Arredondo Suárez): “... las anotaciones en la historia clínica sobre el estado de la testadora que hizo suyas la sentencia interpelada basadas en la apreciación del facultativo de asistencia, no especializado en salud mental, corresponden al veinticinco de mayo de mil novecientos noventa y ocho, fecha distinta y posterior a aquella en que se otorgó el instrumento público cuya impugnación es objeto de la litis, es decir, al día veintidós del expresado mes y año, cuando su enfermedad habia progresado y empeorado su estado general (...) si además de lo expuesto se tiene en cuenta que la aludida testadora en momento alguno de su vida fue declarada incapaz por Tribunal competente, unico medio de irrefutable eficacia para determinar su incapacidad mental para el otorgamiento impugnado (...)”. 
verifique en un espacio de tiempo distinto al de la audiencia notarial, pudiendo diferir, entre un momento y otro la condición psíquica de la persona que nos requiere, situación que se torna excepcionalmente delicada cuando se trata de un testamento, ya que al ser un acto mortis causa, su posible cuestionamiento, mediante proceso judicial de impugnación, se va a realizar después de la muerte de su otorgante, cuando prácticamente es imposible comprobar pericialmente la capacidad mental o volitiva de esta persona. Por otra parte, conforme a la técnica notarial, se vulnera uno de los principios fundamentales que informan la actividad, la unidad de acto".

Tampoco está el notario compelido a solicitar el dictamen pericial en todo momento. Ello es facultativo y no preceptivo del notario. Así lo ha dejado dicho la Sala de lo Civil y de lo Administrativo del Tribunal Supremo en su Sentencia No. 888 de 31 de diciembre del 2003, primer considerando (ponente Carrasco Casi): “... la formula notarial según la cual el Notario actuante afirma, (...) que los otorgantes tienen, a su juicio, la plena capacidad para otorgar el instrumento que autoriza (... ') no es una formalidad de redacción, sino por el contrario, uno de los requisitos esenciales de todo instrumento público, es decir que, el señalado funcionario no puede hacer constar la cuestión relativa a la capacidad legal sin que previa y plenamente le conste; con mayor razón si el quejoso pretende imponerle una obligación al Notario actuante, que en todo caso constituye vía de excepción, como resulta ser en los casos de duda por incapacidad declarada judicialmente la formalidad especial, de que la referida otorgante sea examinada por dos facultativos ${ }^{31}$ (...)", en un caso en que se venía impugnando el testamento otorgado, en razón de que el notario debía preceptivamente solicitar dictamen pericial del facultativo, lo cual como es lógico es facultad exclusiva del notario, sin que sea una carga insoslayable para la eficacia de la escritura pública de testamento autorizada que en el acto notariado haya concurrido un médico, si al notario autorizante no le abrigó dudas la capacidad mental y volitiva del testador.

\section{8. ¿Compele al notario el dictamen del perito?}

El notario español Martínez Díe en su interesante artículo, apoyándose en el Derecho positivo español sostiene con total acierto que "El Notario (...)

31 En este orden ha sido un gazapo de la ponente, a mi juicio, expresar que en el ordenamiento cubano puede otorgar un testamento una persona declarada judicialmente incapacitada, en intervalo lúcido, con la presencia de dos facultativos, pues ni el intervalo lúcido está regulado, ni nuestras resoluciones judiciales constitutivas de la incapacitación de una persona suelen determinar los actos para los cuales se les impide actuar al incapacitado, de modo que le sea permisible al incapacitado testar, lo cual no sería contra Derecho, pues el artículo 30 del Código Civil lo habilitaría, se me ocurre el clásico supuesto del pródigo, a quien no le debe restringir la capacidad para testar. Otro entuerto sería, en el ordenamiento familiar cubano, cómo se complementaría el ejercicio de la capacidad de quien se le restringe parcialmente tal ejercicio por prodigalidad. 
para emitir válidamente un juicio de capacidad debe atenerse a los principios de inmediación, de investigación y responsabilidad personal, de donde se infiere que, para formar criterio sobre este particular, sólo pueda apoyarse en su propio examen, personal y directo, del interesado" 32 , tal criterio tiene como sustento esencial sus conocimientos jurídicos, "por lo que un juicio adverso o favorable respecto de la capacidad de una persona no puede confundirse con un dictamen médico ni psiquiátrico" 33 , juicio que es de su exclusiva incumbencia y neta responsabilidad, "quien no puede desplazarla a los especialistas que hayan podido asistir (...)"34. Para más abundar el también notario español Gómez TABoAdA ha apuntado que "En efecto, el notario no es un técnico, como podría serlo el médico o el psicólogo. Se debe fiar, sin más, de su propio criterio” ${ }^{35}$. El propio autor hace un análisis agudo e interesante sobre qué reglas o pasos debe tener en cuenta el notario para dar el preciado juicio, recalcando en el carácter preventivo y auxiliar del dictamen médico que en cualquier caso no exime al notario de la responsabilidad que asume por el juicio de capacidad.

Tampoco se trata, y este es uno de los tópicos a tratar, que concurra cualquier médico. A mi juicio, el médico que debe apreciar la capacidad volitiva del otorgante, solicitado a instancia del notario, deberá cumplir ciertos requisitos de titulación, incluso comprobados por el notario en el momento de su concurrencia. Es de lamentar que el citado Dictamen No. 3/2004 de 5 de octubre no haya abundado en tal importante particular, de modo que no deja esclarecido la especialidad médica del facultativo que concurra en el acto de autorización del instrumento. Desde una visión integradora del Derecho vigente, habrá que tener en cuenta que el Consejo de Gobierno del Tribunal Supremo se ha pronunciado a través de su Acuerdo No. 130 de 6 de septiembre del 2002, contentivo de su Dictamen No. 418, que determina la necesaria especialización que han de tener los dos médicos dictaminantes sobre el presunto incapaz en procesos judiciales sobre incapacitación. A tales fines el citado Dictamen, si bien no establece un numerus clausus de especialidades médicas, deja esclarecido "que la obligación por parte del Tribunal de hacer examinar al presunto incapaz por dos médicos distintos, se cumplimenta adecuadamente cuando para ello requiera la intervención de profesionales con preparación especializada en la enfermedad que se dictamina", de manera que aun y cuando el artículo 588 de la Ley de Procedimiento Civil, Administrativo, Laboral y Económico (en lo adelante LPCALE) "no haga expresa referencia en lo que concierne a tal especialización, toda vez que atendiendo al elemental principio

Vid. Martínez Die, R., “El juicio notarial de capacidad...”, cit.p. 65.

Idem.

Ibidem.

Vid. Gómez Tаводda, J., “Capacidad del otorgante...”, cit., p. 334. 
de racionalidad que debe presidir toda decisión judicial, bien pudiera no alcanzarse el efecto corroborador buscado, si se aceptara suficiente en tal sentido el parecer emitido por médicos de especialidad ajena a la que se ocupa del padecimiento del expedientado", de lo cual se colige que serán especialistas en psiquiatría forense, o al menos en psiquiatría general, los profesionales idóneos para dictaminar sobre la ausencia de capacidad de obrar de una persona, a los fines de su incapacitación. Razón por la cual en sede notarial, bien pudiera entenderse que son tales especialistas los que en mejores condiciones pudieran dictaminar, aunque la naturaleza misma de la enfermedad pudiera ser dictaminada por neurólogos, intensivistas, $\mathrm{u}$ otros especialistas con experiencia y conocimientos suficientes como para esclarecer las dudas que le abriga al notario la capacidad de una persona que interesa comparecer en un documento público.

En fecha relativamente reciente el Ministro de Salud Pública ha dictado la Resolución No. 7/2008 de 20 de abril, por la que se crea la comisión médica para la peritación psiquiátrica forense de sujetos vinculados a procesos judiciales y se establece la metodología para el funcionamiento de las comisiones provinciales de peritación psiquiátrica forense en el sistema nacional de salud. Serán los Directores Provinciales de Salud los encargados de nombrar, mediante Resolución, al Jefe y a los miembros de cualquier categoría de las Comisiones Provinciales de Peritación Mental, oídos los criterios de los Grupos y Centros Provinciales de Psiquiatría, Medicina Legal, Psiquiatría Infanto Juvenil y otros que estime convenientes, así como la de los centros de procedencia de los designados. La composición pericial será de tres en los casos civiles, salvo que se trate de proceso de incapacitación judicial, en que serán dos, en cumplimiento de lo legalmente establecido (artículo 588 de la LPCALE). Se nombrará un Presidente, especialista de Medicina Legal o Psiquiatría. Entre los demás peritos miembros de la Comisión se designará el sustituto del Presidente.

Según la citada norma legal se nombrarán peritos, que a los fines de la ley serán Titulares: de forma que completen en la comisión dos psiquiatras y dos médicos legistas, salvo que por el volumen de trabajo del territorio se decida un número mayor de ambos tipos de especialistas. También podrá ser nombrado un psiquiatra infanto juvenil, o más de uno, si el volumen de casos, así lo justifica. Si existen psicólogos con experiencia acreditada en la actividad pueden nombrase como peritos, especialmente para casos infanto juveniles. El desarrollo de la actividad puede determinar que en un territorio se nombre como perito a otros especialistas, como un neurofisiólogo. La composición interdisciplinaria de la comisión hace posible y deseable la realización de interconsultas y asesoramientos entre especialistas; la condición de perito no excluye asumir, de ser solicitado 
por otros peritos actuantes, la de interconsultado o asesor dentro de la propia Comisión, aun cuando ello no represente asumir la responsabilidad pericial.

Como nota curiosa de la mencionada resolución, a pesar de que la competencia para solicitar el peritaje médico-forense se centra esencialmente en el terreno judicial, al menos como excepción, "podrán examinarse personas en razón de establecer su aptitud mental para realizar determinado trámite ante instancias como Notarias e Instituto de la Vivienda, por solicitud expresa de éstos y solo con relación a acciones concretas pendientes de realizar en las mismas, sin pronunciarse sobre la incapacidad o capacidad global de las personas, o sobre su estado al haberlas realizado si ya lo hicieron, lo que es de la exclusiva competencia de las Salas de lo Civil de los Tribunales". No quepa dudas que, en lo que al ámbito notarial concierne, en el anexo de la resolución se admite, al menos con carácter excepcional, la solicitud de examen pericial cuando se pretende otorgar válidamente un acto jurídico y el notario tiene dudas sobre la capacidad del pretenso otorgante, es claro que se trata de casos puntuales para dictaminar sobre la capacidad mental y volitiva del sujeto para ese acto en concreto (acto en tiempo presente), no para dictaminar sobre su capacidad con alcance general o para dictaminar sobre la existencia de esta en un acto pretérito, supuestos estos dos últimos que le compete evaluar exclusivamente al tribunal a través del proceso de jurisdicción voluntaria de incapacitación judicial o el ordinario de impugnación de un acto jurídico en concreto por ausencia de ejercicio de la capacidad ex artículo 67 b) del Código Civil, respectivamente.

\section{9. ¿Qué consecuencias provoca el error notarial en la apreciación de la capacidad, cuáles la ausencia de mención del juicio de capacidad en la comparecencia del instrumento público, y qué otras la apreciación dolosa o falsaria de la capacidad del compareciente a sabiendas de que no la tiene?}

Resulta necesario delimitar los efectos jurídicos que puede conllevar distintas situaciones conectadas con el juicio notarial de capacidad, como su apreciación errónea, su apreciación dolosa o falsa y la ausencia de apreciación como mención auténtica en el instrumento público.

Precisamente me referiré a la tercera de las situaciones apuntadas. En el Derecho cubano el juicio de capacidad es un requisito de solemnidad en sede testamentaria. El artículo 483.2 del Código Civil lo deja suficientemente explícito: " $E l$ notario se cerciora de que el testador tiene la capacidad legal para otorgar testamento, y lo hace constar", no es suficiente que el notario aprecie la capacidad del otorgante. Es 
cierto que la propia autorización de un instrumento público lleva implícita el control del ejercicio de la capacidad jurídica de cada otorgante, pero en nuestro Derecho no resulta suficiente, ni tampoco prosperaría la tesis que en otros ordenamientos tendría éxito de que en la autorización hay una implícita aprobación notarial del ejercicio de la capacidad jurídica del otorgante. El citado precepto del Código Civil lo eleva a requisito de solemnidad en materia testamentaria, en tanto que el Reglamento notarial lo hace extensivo a todos los instrumentos públicos, ya sean escrituras (vid. artículo $64 \mathrm{c}$ )) o actas (vid. artículo $81 \mathrm{c}$ )). La mención auténtica del juicio de capacidad ha de constar en todo instrumento público protocolizable, sin excepción, al menos en el dictado del Reglamento notarial. Autenticidad que viene dada por provenir del notario, y que hace certero o indubitado no el juicio de capacidad mismo, sino el hecho de haber apreciado o valorado la capacidad natural o volitiva del sujeto. Eso sí, no se necesita de ciertas palabras o frases sacramentales para consignar en el instrumento público el juicio de capacidad. Ello fue advertido incluso por los primeros autores que en España escribieron sobre el tema ${ }^{36}$.

La ausencia del juicio de capacidad conduce a la nulidad del instrumento público al amparo del artículo 16 b) de la Ley notarial que expresamente reconduce este supuesto a una de las causales de nulidad instrumental, particular insubsanable, solo posible de enmendar con la autorización de un nuevo instrumento público, si existieren posibilidades para ello, incluso en el caso de que el propio tribunal apreciare prueba fehaciente del ejercicio de la capacidad del otorgante, lo cual en mi criterio es un exceso de formalismo que a nada conduce, salvo a potenciar supuestos de nulidad instrumental ${ }^{37}$. Sobre la necesidad de que el juicio de capacidad se haga constar en el instrumento público, una vez comprobada la capacidad del otorgante para el acto o negocio que pretende instrumentar, se ha pronunciado el Tribunal Supremo llegando incluso a considerar que "... la fórmula notarial según la cual el Notario actuante afirma, '... que los otorgantes tienen, a su juicio, la plena capacidad para otorgar el instrumento que autoriza...' no es una formalidad de redacción, sino por el contrario, uno de los requisitos esenciales de todo instrumento público, es decir, que el señalado funcionario no puede hacer constar la cuestión relativa a la

36 Según Sancho-Tello y Burguet, Vicente, Derecho Notarial de España, Librería de Ramón Ortega, Valencia, 1900, pp. 141-142, al estudiar el juicio de capacidad en los actos de última voluntad, con apoyatura en la Sentencia de 24 de diciembre de 1896 del Tribunal Supremo español, la expresión de dicho juicio en el instrumento no requiere que "se consigne en párrafo separado ni con las palabras precisas é insustituibles de á su juicio, bastando que de cualquier modo ó con locución distinta, exprese clara y evidentemente su parecer respecto á dicha capacidad".

37 Sin embargo, en el ordenamiento jurídico español esta no es la posición que prevalece. Sostiene Tamayo Clares que "La falta del juicio de capacidad o su inexpresión documental no es causa de nulidad formal en los actos inter vivos, ya que ha de entenderse implícita en la autorización, y puede ser subsanada, aunque solo por el Notario autorizante, en diligencia o en acta separada (...). Vid. Tamayo Clares, M., Temas..., cit., p. 136. 
capacidad legal sin que previa y plenamente le conste (...)" (Sentencia No. 888 de 31 de diciembre del 2003, primer Considerando, ponente Carrasco Casi), al propio tiempo que se ha dicho que "... el requisito más importante que la Ley de las Notarias Estatales asi como su Reglamento establecen con relación a la capacidad de los comparecientes de los Instrumentos Públicos Notariales, es la obligación de hacer constar en toda escritura que los mismos tienen capacidad legal necesaria para intervenir en el acto o contrato a que la escritura se refiere, cuya circunstancia se determinará a juicio del notario, no bastando que lo consigne asi en el instrumento apoyándose en el solo dicho de los otorgantes, sino que es obligatorio y necesario que este funcionario público también compruebe y determine a su juicio, dicha constancia (...)" (Sentencia No. 314 de 30 de octubre del 2009, único Considerando, ponente Acosta Ricart).

Cuestión distinta resulta la apreciación equivocada o errónea de la capacidad del compareciente. El notario no es un perito en la materia, lo cual justifica dentro de los límites de permisiblidad racional, el error en la apreciación de la capacidad de obrar de la persona, cuando a posteriori se demuestra que esta carece de ella para el acto o negocio que pretende concertar. Dado que la capacidad se presume y el notario debe actuar conforme con el principio pro capacitate, el error en la valoración de la capacidad, conduce a la nulidad del acto jurídico conforme con el artículo 67 b) del Código Civil. Si la persona carece de discernimiento al momento de concertar el acto, no está apta para medir los efectos jurídicos del acto o negocio que quiere concertar, ni tampoco de autogobernarse, no habrá entonces manifestación de voluntad válida y eficaz. Caemos en el terreno de la nulidad absoluta, y no relativa, según los dictados del vigente Código Civil. La ausencia de capacidad de obrar en el sujeto le impide el ejercicio de sus derechos, en consecuencia, cualquier acto que concierte está condenado a la nulidad, acción que podrá ser ejercitada en todo momento por parte interesada o por el fiscal, por el interés público que reviste (vid. artículo 68 del Código Civil). No hay alternativas a la convalidación como modo de sanación del acto jurídico. Este está condenado a ser declarado nulo en cualquier momento, y se entiende que nunca ha producido los efectos jurídicos, al menos los queridos o buscados por el autor del acto o negocio jurídico. Como se trata de una presunción iuris tantum, demostrado en la sustanciación del proceso, dicha presunción se desmorona (vid. en este orden las sentencias Nos. 669 de 30 de septiembre del 2004, segundo Considerando, ponente Arredondo Suárez, 265 de 20 de abril del 2005, segundo Considerando, ponente González García, y como más ilustrativa la 285 de 7 de octubre del 2009. Primer Considerando. Ponente Arredondo Suárez, a cuyo tenor se deja dicho que "... resulta justificada de manera fehaciente e indubitada la presencia de circunstancias personales que afectan en sentido restrictivo 
la capacidad en uno de los intervinientes en el acto de permuta cuya ineficacia se acusa, de modo que padece vicio que determina su nulidad al remontarse tales padecimientos al momento de su otorgamiento, convicción a la que se arriba partiendo de aceptar que la integridad mental, por ser aptitud natural o atributo normal del ser humano, se presume en toda persona que no haya sido previamente declarada incapacitada por tribunal competente, pero es que se trata de presunción iuris tantum, destruible por contundente prueba en contrario, obviamente a cargo de quien la alega, y de fuerza tal que por si baste para enervar el juicio notarial sobre capacidad emitido por el funcionario autorizante del acto juridico de que se trate, dación de fe que subsume la apreciación personal del Notario al respecto y documenta no merecerle duda la capacidad natural del otorgante (...)").

Tema mucho más peliagudo lo es, la aseveración por el notario de haber realizado el juicio de capacidad, esto es, de haber controlado la capacidad volitiva de los comparecientes, cuando no lo ha hecho, o cuando contribuya a falsear la verdad en el sentido de apreciar la capacidad de obrar de un sujeto a sabiendas de que este no tiene discernimiento para el acto en concreto que pretende realizar, supuesto que pudiera subsumirse en el inciso b) del artículo 250 del vigente Código Penal que incluye en el tipo penal de falsificación de documento público la actuación del agente que "contribuya a consignar en un documento público, datos, declaraciones o hechos inexactos relativos al acto de que el documento es objeto". En tales circunstancias, estaríamos en presencia de una falsedad ideológica. Particular sobre el que algún autor ha expresado su duda, pues considera que solo en sentido lato pudiera entenderse como un hecho narrado por el notario, el juicio de capacidad ${ }^{38}$.

\section{0. ¿Cómo valora el Tribunal Supremo el juicio notarial de capacidad?}

El posible error en la apreciación notarial de la capacidad natural de la persona, fundamentalmente cuando esta se arropa de la condición de testadora, es una de las razones por las que con mayor frecuencia se impugnan los actos jurídicos en sede judicial. Hasta cierto punto es comprensible. Es quizás el juicio más vulnerable de todos los que el notario da. Lógicamente es el más probabilístico. El notario no es un perito, solo aprecia o se cerciora de la capacidad natural de la persona, entendido el término cerciorar como sinónimo de atestiguar, aseverar, con los límites en que tal aseveración ha de comprenderse. Adpero, para el Tribunal Supremo el juicio notarial de capacidad actúa como un valladar, difícil de expugnar.

38 Así, Torres Escamez, S., “Un estudio sobre...”, cit., p. 244. 
Así, la propia Sala de lo Civil y de lo Administrativo del Alto Foro ha apoyado el juicio notarial de capacidad en la fe pública de la que está dotado el notario, lo cual es cierto, si bien el manto de la fe pública no se extiende hacia la verdadera certeza del juicio de capacidad. La verdad sobre la capacidad natural, de entender y de querer del agente, no está cubierta por la fe pública, y sí tan solo el juicio mismo dado por el notario, o sea, el aspecto formal o instrumental que todo juicio notarial encierra. Bajo la fe pública está la verdad formal, pero no la material, porque el juicio de capacidad no es una declaración de verdad, sino es una declaración probabilística, sometida con buen gusto al arbitrio judicial ${ }^{19}$. Compete al tribunal determinar cuan errado estuvo el notario cuando apreció discernimiento y voluntad en un sujeto, que a la postre no existía, o cuanto menos, estaban viciados.

Para el Alto Foro merece "... especial atención el juicio de capacidad dado por el notario actuante (...), pues no puede soslayarse que en todo caso tiene como función especifica del poder del Estado la de la Fe Pública, que equivale a atestiguar solemnemente la veracidad de un hecho con trascendencia jurídica (...)" (Sentencia No. 430 de 31 de julio del 2003, único Considerando, ponente Acosta Ricart), “... funge como irrebatible la fe pública notarial, dada por el fedatario actuante en cuanto a la capacidad de la testadora como compareciente (...), cuyo depositario es el notario, dirigida a garantizar determinados derechos y obligaciones, acreditando la veracidad de determinados hechos y actos que de una manera directa afecten la actuación de la legalidad (...), resultando por tanto el juicio de capacidad acerca de los comparecientes, uno de los aspectos probatorios del instrumento público (...)”.(Sentencia No. 615 de 20 de diciembre del 2007, segundo Considerando, ponente Acosta Ricart). El juicio notarial de capacidad actúa como una fuerte presunción iuris tantum, solo destruible con un contundente material probatorio "no es una formalidad de redacción, sino por el contrario, uno de los requisitos esenciales de todo instrumento público, es decir, que el señalado funcionario no puede hacer constar la cuestión relativa a la capacidad legal sin que previa y plenamente le conste (...)" (Sentencia No. 888 de 31 de diciembre del 2003, primer Considerando, ponente Carrasco Casi). "(A)l emitir el fedatario autorizante el juicio de capacidad plena del testador erige presunción iuris tantum de certeza de tal circunstancia y es a dicha parte recurrente impugnante del acto a quien corresponde la carga probatoria en contrario, sin que

39 Expone Torres Escamez que "la apreciación notarial de la capacidad lleva consigo un juicio sobre la capacidad natural del otorgante, una calificación jurídica referida a su capacidad de obrar y legal y una dación de fe en cuanto a la propia actividad del notario a ese respecto". El propio autor cita en apoyo de su criterio la Resolución de la DGRN de 7 enero de 1992 con énfasis en que el notario "se limita a emitir un juicio, no una declaración de verdad, y la fe pública sólo ampara la declaración de que tal parecer ba sido formulado". Vid. Torres Escamez, S., "Un estudio sobre...”, cit., p. 222. 
el demandado venga obligado en consecuencia a establecer hecho alguno en aval del acto jurídico materializado (...)". (Sentencia No. 240 de 21 de septiembre del 2010, segundo Considerando, ponente González García). El juicio notarial de capacidad, salvo prueba en contrario resulta, incluso vinculante, sin que con ello se desdiga -según el criterio del Alto Foro-, su naturaleza de presunción iuris tantum, si bien con un matiz especial "... pues aun cuando dicha manifestación es ejercicio de la fe pública notarial, la afirmación de capacidad no acredita un hecho sino que constituye un juicio lógico, o apreciación y por tanto como tal, respecto al mismo sólo debe estimarse una presunción iuris tantum, y no ha de suponerse que haya de aceptarse como indiscutible, ya que podrá ser destruida por ulteriores pruebas demostrativas en contrario, sin negar lo dificil que en la realidad cotidiana resulta, de donde para que alcance éxito una acción de esta naturaleza se precisa la plena demostración que la persona justo al preciso momento de la realización del acto jurídico que se impugna, no tenía capaz suficiente para discernir (...)". (Sentencia No. 264 de 30 de septiembre del 2010, segundo Considerando, ponente Acosta Ricart). En consecuencia, sin el arsenal probatorio el cual deberá ser desplegado por el actor en la fase probatoria de la sustanciación del proceso que demuestre la falta de discernimiento de la persona de cuyo ejercicio de la capacidad se dubita, no prosperará la pretensión argüida en la demanda, “... lo que es inequívoca consecuencia de haber estimado acreditada la capacidad plena de la testadora para tal otorgamiento, revestido de la presunción iuris tantum de certeza que le confiere la aquiescencia del notario autorizante (...)" (Sentencia No. 344 de 22 de noviembre del 2010, segundo Considerando, ponente González García).

Compete al tribunal valorar con racionalidad el juicio notarial de capacidad, en tanto este no es una verdad irrebatible, aun cuando vaya dotado de esa fuerte presunción iuris tantum a la que una y otra vez se refiere el Alto Foro. Por ello, en algunas ocasiones, si bien contadas, el juicio de capacidad logra destruirse ante la veracidad de las pruebas aportadas que permiten que aquel sea refutado, elocuente demostración de su valor probabilístico y no de verdad incombatible. En su Sentencia No. 285 de 7 de octubre del 2009, primer Considerando, ponente Arredondo Suárez se ha dejado dicho que "... resulta justificada de manera fehaciente e indubitada la presencia de circunstancias personales que afectan en sentido restrictivo la capacidad en uno de los intervinientes en el acto (...) cuya ineficacia se acusa, de modo que padece vicio que determina su nulidad al remontarse tales padecimientos al momento de su otorgamiento, convicción a la que se arriba partiendo de aceptar que la integridad mental, por ser aptitud natural o atributo normal del ser bumano, se presume en toda persona que no haya sido previamente declarada incapacitada por tribunal competente, pero es que se trata de presunción iuris tantum, destruible por contundente prueba en contrario, obviamente a cargo de quien la alega, 
y de fuerza tal que por si baste para enervar el juicio notarial sobre capacidad emitido por el funcionario autorizante del acto jurídico de que se trate, dación de fe que subsume la apreciación personal del Notario al respecto y documenta no merecerle duda la capacidad natural del otorgante (...)”. Asimismo en su Sentencia No. 113 de 30 de abril del 2010, primer Considerando, ponente Arredondo Suárez, en la que se dice que "... quedó acreditado que al momento de otorgar el testamento que se impugna, la causante estaba afectada en sus facultades mentales de manera que le impedía manifestar válidamente su voluntad, pues aunque consta el juicio de capacidad de la funcionaria que autorizó el documento notarial, no es posible obviar que dicha dación de fe expresa la apreciación personal de la Notaria actuante al respecto, patentizando no merecerle duda la capacidad natural de la otorgante, pero puede ser destruida mediante prueba fehaciente e indubitada (...)".

La negativa del notario a la autorización del instrumento ha de fundarse en razones justificadas, razonadas, sobre la base de dudas certeras que le posibiliten concluir que la persona que pretende comparecer en el instrumento público, carece de discernimiento para autogobernarse y poder determinar el alcance de los efectos del acto o negocio a instrumentar. En este orden, el notario debe explorar las potencialidades del sujeto y no limitarse a un mero sondeo de su voluntad, sobre la base del prejuicio que puede generar ciertas enfermedades, asociadas directamente con la disminución de las facultades volitivas y mentales de la persona. Eso sí, una vez que el notario da un juicio positivo sobre la capacidad del sujeto, este se erige en esa fuerte presunción iuris tantum a la que tantas veces alude el Alto Foro.

De ahí que el juicio notarial de capacidad, solo puede ser destruido por prueba fehaciente e indubitada, particulares de los que carece “... el (...) certificado médico y el resumen de historia clinica que, aunque mencionan la demencia senil entre las patologías clinicas que padeció el testador, fueron emitidos año y medio después del deceso de aquel por facultativo que no consta sea especialista en psiquiatría, siendo eminentemente subjetivo inferir que en la fecha del otorgamiento de sus actos de última voluntad carecía de facultades volitivas (...)" (Sentencia No. 178 de 30 de junio del 2010. Primer Considerando. Ponente Arredondo Suárez), “... las anotaciones en la bistoria clínica sobre el estado de la testadora que bizo suyas la sentencia interpelada basadas en la apreciación del facultativo de asistencia, no especializado en salud mental (...)" (Sentencia No. 266 de 28 de febrero del 2001, primer Considerando, ponente Arredondo Suárez), o "... el hecho de que se consignara en el instrumento público cuestionado que la causante no sabia leer y escribir cuando si poseía tales conocimientos, de abi que sería eminentemente subjetiva cualquier valoración al respecto (...)" (Sentencia No. 43 de 26 de febrero del 2010, único Considerando, ponente Arredondo Suárez). 
Aunque quizás más discutida, al parecer el Alto Foro tampoco le da el valor probatorio que en Derecho pudiera tener la autopsia psicológica con la cual se pretende reconstruir la personalidad psicológica de una persona fallecida, sobre todo en los supuestos de testadores, cuyo testamento se impugna por ausencia de ejercicio de la capacidad jurídica al momento de su otorgamiento, calificada por dicho tribunal como "... una prueba inútil y tendente a dilatar innecesariamente el proceso, pues resulta improbable pudiera llegarse a resultado exitoso con relación a lo pretendido con dicha prueba, a partir de los elementos de los que habrían de servirse los especialistas para dar un dictamen certero, prueba esta que por lo delicado que resulta emitir criterio serio y cientificamente razonado sobre la capacidad de obrar de una persona en tiempo pretérito, máxime cuando la misma ya ha dejado de existir, en numerosos casos los especialistas en mérito de su responsabilidad y prestigio profesional evaden sobre fundamentos razonados y razonables, pronunciarse al respecto (...)" (Sentencia No. 264 de 30 de septiembre del 2010, primer Considerando, ponente Acosta Ricart).

\section{Referencias Bibliográfica}

\section{Fuentes doctrinales}

Ballarín Marcial, Alberto, "Naturaleza y clases de 'juicios' del notario “, en Anales de la Academia matritense del Notariado, tomo XXXV, Madrid, 1996; CÁmARA Álvarez, Manuel de la, "El notario latino y su función", en Revista de Derecho Notarial, año LXXVI, abril-junio 1972; Chikoc Barreda, Naiví, Capítulo VI "Clasificación de los testamentos", en Derecho de Sucesiones, bajo mi coordinación, Félix Varela, La Habana, 2004; Giménez-Arnau, Enrique, Derecho Notarial, Ediciones Universidad de Navarra, Pamplona, 1976; Gómez Taboada, Jesús, "Capacidad del otorgante y vicios del consentimiento", en Derecho Notarial, tomo II, Leonardo B. Pérez Gallardo e Isidoro Lora-Tamayo Rodríguez (coordinadores), Félix Varela, La Habana, 2007; LópEz Garzón, José, "Titularidad y fe de conocimiento", en Revista de Derecho Notarial, No. 7, Madrid, 1955; Martínez Die, Rafael, "El juicio notarial de capacidad en su dimensión negativa: régimen jurídico y consecuencias", en La Notaría, No. 2, mayo 2002; Martínez-Gil Vich, Ignacio, "Comentarios al artículo 157 del Reglamento notarial", en Nueva legislación notarial comentada, tomo I - Legislación notarial, Colegio Notarial de Madrid, 2007; PARRa Benítez, Jorge, El nuevo régimen de incapaces en el derecho colombiano. Ley 1306 de 2009, Pontificia Universidad Javeriana, Grupo editorial Ibáñez, Depalma, Bogotá- Buenos Aires, 2011; PÉrez Gallardo, Leonardo B., "Intervención testifical en los instrumentos públicos notariales: más allá de una reliquia histórica”, en Derecho Notarial, tomo II, bajo la coordinación del propio autor e Isidoro Lora-Tamayo Rodríguez, Félix Varela, La Habana, 2007; "Concurrencia del perito en el documento público notarial”, en Revista del Instituto de Derecho e Integración, Cole- 
gios de escribanos de la provincia de Santa Fe, Rosario, Argentina, año 2, No. 4, 2010; Pérez Silveira, Maelia Esther, “Comentarios al artículo 20”, en Comentarios al Código Civil cubano, tomo I - Disposiciones preliminares y Relación jurídica, volumen I (artículos 1 al 37), bajo mi dirección, Félix Varela, La Habana, 2013; Rodríguez Adrados, Antonio, "El documento en el Código Civil", en Escritos jurídicos, tomo III, Colegios Notariales de España, Madrid, 1996; "Cuestiones de técnica notarial en materia de actas”, en Escritos jurídicos IV, Colegios Notariales de España, Madrid, 1996; Torres Escamez, Salvador, "Un estudio sobre el juicio de capacidad", en Revista jurídica del notariado, No. 34, Madrid, 2000; Sancho-Tello y Burguet, Vicente, Derecho Notarial de España, Librería de Ramón Ortega, Valencia, 1900; Solís Villa, Carlos, y Francisco Javier Morillo, "Comentarios al artículo 198 del Reglamento notarial", en Nueva legislación notarial comentada, tomo I - Legislación notarial, Colegio Notarial de Madrid, 2007; Tamayo Clares, Manuel, Temas de Derecho Notarial, 5a edición, Ilustre Colegio Notarial de Granada, Granada, 2001; VAldés Díaz, Caridad del C., "Comentarios al artículo 30", en Comentarios al Código Civil, tomo I - Disposiciones preliminares. Relación jurídica, volumen I (artículos 1 al 37), bajo mi dirección, Félix Varela, La Habana, 2013.

\section{Fuentes legales}

Código Civil de la República de Cuba, Ley No. 59/1987 de 16 de julio, anotado y concordado por Leonardo B. Pérez Gallardo, Ciencias Sociales, La Habana, 2011; Código Civil del Reino de España de 6 de octubre de 1888, 24a edición, Tecnos, Madrid, 2005; Ley de Procedimiento Civil, Administrativo, Laboral y Económico, Ley No. 7/1977 de 19 de agosto, Editorial Pueblo y Educación, 1a reimpresión, La Habana, 1983, modificada por el Decreto-Ley No. 241/2006 de 26 de septiembre en Gaceta Oficial de la República de Cuba, Extraordinaria, No. 33, de 27 de septiembre del 2006; Pérez Gallardo, Leonardo B., Julliet Almaguer Montero y Nancy C. Ojeda RoDRíguez (compiladores) Compilación de Derecho Notarial, Félix Varela, La Habana, 2007. 